PAPER

\title{
Cerebral amyloid angiopathy in traumatic brain injury: association with apolipoprotein $E$ genotype
}

\author{
P D Leclercq, L S Murray, C Smith, D I Graham, J A R Nicoll, S M Gentleman
}

J Neurol Neurosurg Psychiatry 2005;76:229-233. doi: 10.1136/jnnp.2003.025528

See end of article for authors' affiliations

Correspondence to:

Dr S M Gentleman Division of Neuroscience and Psychological Medicine, Imperial College London, Charing Cross Campus, St Dunstan's Road, London W6 8RP UK; s.gentleman@ imperial.ac.uk

Received 9 October 2003 In revised form

19 May 2004

Accepted 24 May 2004

\begin{abstract}
Objective: In view of the association of the apolipoprotein $E(A P O E) \in 4$ allele with poor outcome after traumatic brain injury we determined the frequency of cerebral amyloid angiopathy (CAA) and the extent of haemorrhagic pathology in relation to APOE genotype in an autopsy series of 88 head injured cases. Methods: Tissue sections from the frontal and temporal lobes were immunostained for amyloid- $\beta$ peptide $(A \beta)$ and stained for Congo red to identify vascular amyloid pathology. A semiquantitative assessment of contusions, the total contusion index, was used to estimate the severity of the haemorrhagic pathology. $A P O E$ genotypes were determined by polymerase chain reaction of genomic DNA extracted from paraffin embedded tissue sections.

Results: CAA was present in $7 / 40(18 \%) \epsilon 4$ carriers compared with $1 / 48(2 \%)$ non- $\epsilon 4$ carriers $(p=0.021$, $95 \%$ confidence interval (CI) for difference in proportions with CAA $3 \%$ to $29 \%$ ) with $6 / 40$ (4 with CAA) $\in 4$ carriers being homozygotes. Thus the risk of having CAA for $\epsilon 4$ carriers was 8.4 times that for the non- $\epsilon 4$ carriers. However, there was no clear tendency for patients with CAA to have more severe or more numerous contusions (median contusion index 19 (CAA) $v 14.5, p=0.23,95 \% \mathrm{Cl}$ for difference in medians -5 to 14 ).

Conclusions: Presence of CAA in head injured cases was significantly associated with possession of an $A P O E \in 4$ allele but not with the severity of contusions.
\end{abstract}

$\mathrm{T}$ he apolipoprotein E (APOE) gene has three common alleles $(\epsilon 2, \epsilon 3$, and $\epsilon 4)$ producing corresponding isoforms of the protein: ApoE2 (Cys 112, Cys 158), ApoE3 (Arg 112, Cys 158), and ApoE4 (Arg 112, Arg 158). Accumulated evidence suggests that inheritance of an $A P O E \in 4$ allele renders some individuals more susceptible to a poor outcome following traumatic brain injury, ${ }^{1-3}$ spontaneous intracerebral haemorrhage, ${ }^{4-6}$ and possibly subarachnoid haemorrhage ${ }^{7}$ but not apparently, after ischaemic stroke. ${ }^{910}$ This varying influence of $A P O E$ genotype on outcome in different forms of acute brain injury raises the possibility that the underlying mechanism may involve vascular factors and enhanced susceptibility to haemorrhage.

Cerebral amyloid angiopathy (CAA) is a pathological condition characterised by the deposition of amyloid in cerebral cortical and leptomeningeal blood vessels. The classification of CAA is based on the specific protein deposited as amyloid and on whether the disease is inherited or sporadic. ${ }^{11-13}$ The hereditary forms of the disease are very uncommon whereas sporadic CAA, where there is aggregation of amyloid $\beta$ protein $(A \beta)$, is relatively common. ${ }^{14}{ }^{15}$ Sporadic CAA is strongly age related, affecting over a third of individuals above 60 years of age, ${ }^{16-18}$ and it is present in $80-90 \%$ of cases with late onset Alzheimer's disease. ${ }^{19-22}$ CAA manifests as circumferential deposition of $\mathrm{A} \beta$ in the media and adventitia with consequent thickening of the walls of blood vessels. This induces degeneration of the smooth muscle cells in the media of arterioles and small arteries, which weakens their walls rendering them brittle and unable to sustain large fluctuations in the cerebral blood flow. ${ }^{12}{ }^{13}{ }^{23}$ CAA is usually clinically asymptomatic but occasionally patients present with spontaneous superficially located haemorrhages, which may be multiple or recurrent. Both symptomatic and asymptomatic CAA have been shown to be strongly associated with possession of $A P O E \in 4 .^{20}$

On the basis of these observations, we hypothesised that $A P O E \in 4$ carriers who sustain a head injury may be more likely to have CAA and may develop more frequent and severe haemorrhagic contusions as a result of their vascular pathology. This mechanism could explain, in part, why APOE $\epsilon 4$ is associated with poor outcome after traumatic brain injury.

\section{METHODS}

\section{Case material}

Formalin-fixed paraffin embedded brain tissue and associated clinical information for 88 cases of traumatic head injury were obtained from the archive of the Department of Neuropathology, Institute of Neurological Sciences, Glasgow. All work carried out with this tissue was approved by the ethics committee of the Southern General Hospital. For each case, paraffin sections were selected from both the frontal and medial temporal lobes. The immunohistochemistry was assessed blind to clinical details, pathological features, and $A P O E$ genotypes.

\section{Determination of APOE genotypes}

The $A P O E$ genotypes of the cases were already available from a previous study ${ }^{24}$ and had been determined by amplifying genomic DNA extracted from formalin-fixed tissue using a published method. ${ }^{25}$

\section{Immunohistochemistry}

Paraffin sections were pretreated in $80 \%$ formic acid solution for eight minutes and incubated overnight at $4{ }^{\circ} \mathrm{C}$ with an antiserum raised against residues 18-22 of the human form of A $\beta$ (clone 1E8, 1:2000 dilution; Glaxo SmithKline, UK). A $\beta$ immunoreactivity was detected using the avidin biotin peroxidase method (ABC Elite kit, Vectors Laboratories, UK) and diaminobenzidene $(\mathrm{DAB})$ as the chromogen. Sections were counterstained with Meyer's haematoxylin. The alkaline

Abbreviations: $A P O E$, apolipoprotein $\mathrm{E}$; $\mathrm{CAA}$, cerebral amyloid angiopathy; $A \beta$, amyloid $\beta$-protein 
method of Congo red ${ }^{26}$ was also used to stain amyloid and birefringence was visualised under polarised light.

\section{Total contusion index}

The contusion index is a measure based on the product of the extent (rated 1-3) and depth (rated 1-4) of contusions in any particular region of the brain. Therefore, a higher numerical index indicates more severe damage. The assessment is carried out both macroscopically and microscopically because there is usually an area of non-haemorrhagic necrosis deep to the haemorrhage, which cannot be assessed macroscopically. By combining the contusion indices from different areas of the same brain it is possible to calculate a total contusion index for that brain. ${ }^{27}$

\section{Statistical analysis}

Median values between two groups were compared using the Mann-Whitney test and confidence intervals (CI) and among three groups using the Kruskal-Wallis test. Proportions were compared using Fisher's exact test. Confidence intervals for differences in proportions were calculated using a normal approximation although it is acknowledged that this may be inaccurate for small samples.

\section{RESULTS}

The head injury cohort consisted of 65 males and 23 females with a median age of 29.5 years ranging from less than a year old to 79 years of age. The median survival time was 46.5 hours and ranged from four hours to 24 days.

\section{Prevalence of CAA in traumatic brain injury}

Vascular amyloid deposition, identified by Congo red staining and $A \beta$ immunoreactivity, was present in $8 / 88(9 \%)$ trauma cases examined. All eight cases displayed $A \beta$ deposits in the walls of small arteries and arterioles in the frontal and temporal cortices and the overlying leptomeninges ranging from mild to severe CAA (fig 1 ). In one case ( 21 year old male) the deposits were only in the leptomeninges (fig $1 \mathrm{~A}$, B). This case was the youngest case with CAA, who survived 10 days following a vehicle accident and showed relatively severe contusional pathology illustrated by a total contusion index of 28. His $A P O E$ genotype was $€ 3 \in 4$. The clinical features of those with and without CAA are given in table 1 . Head injured patients with CAA were significantly older than those without CAA ( $p=0.005,95 \%$ CI for median difference 9 to 41 years). There was no statistically significant difference between the two groups with regard to cause of injury or survival time. Seven of the eight $(88 \%)$ patients with CAA had accompanying deposits of $A \beta$ in the form of plaques in the cerebral cortex. CAA without cortical plaques was identified in one case only. Cortical $A \beta$ plaques were less common $(17 / 80 ; 21 \%)$ among the patients without CAA $(\mathrm{p}<0.001,95 \% \mathrm{CI}$ for difference in proportions with $\mathrm{A} \beta$ plaques $43 \%$ to $91 \%$ ).

\section{APOE genotypes of head injured patients with CAA}

Six of the 88 trauma cases were $A P O E € 4$ homozygotes, which corresponds to about $7 \%$ of the cohort. This was slightly higher than expected but the $A P O E \in 4$ allele is known to be associated with poor outcome following traumatic brain injury, including mortality. The $A P O E \in 4$ allele frequency was higher in the patients with CAA $(11 / 16 ; 69 \%)$ than in those without $(35 / 160 ; 22 \%)$, and half of patients with CAA (4/8) were $A P O E \in 4$ homozygotes compared with $2 \%(2 / 80)$ of those without CAA. Nearly all of the patients with CAA were $A P O E \in 4$ carriers $(7 / 8 ; 88 \%)$ compared with $33 / 80$ (41\%) patients without CAA (table 1). The degree of A $\beta$ accumulation in the media and adventitia was also more pronounced in $\epsilon 4$ homozygotes (fig $1 \mathrm{E}-\mathrm{H}$ ) than in $\epsilon 4$ heterozygotes
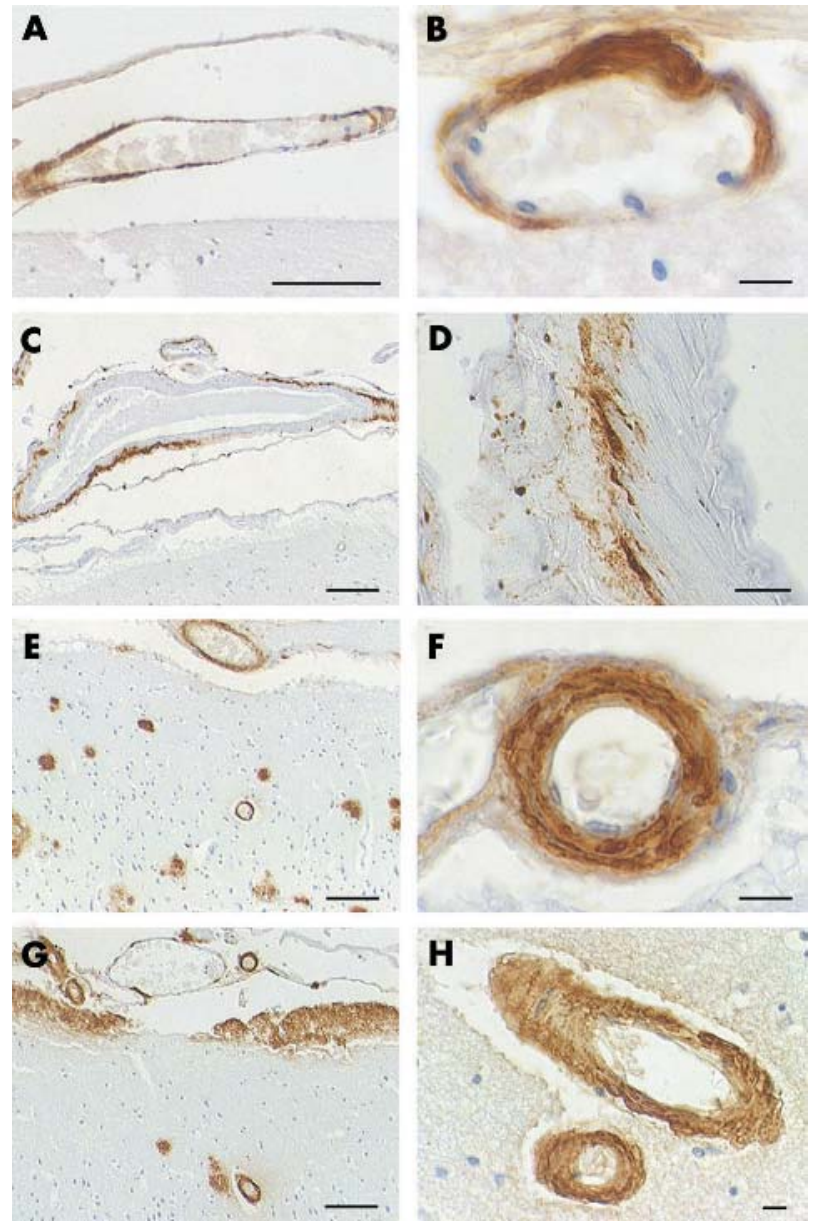

Figure 1 (A-H) Immunoperoxidase labelling for amyloid- $\beta(A \beta)$ peptide illustrating cerebral amyloid angiopathy (CAA) severity in postmortem tissue of head injured patients. CAA was present in $9 \%$ of trauma cases with nearly all showing $A \beta$ plaques in the cortical grey matter of the frontal and temporal lobes $(\mathrm{C}-\mathrm{H})$. The exception was a 21 year old male with a survival time of 10 days who had partial deposition of $A \beta$ only in the leptomeninges $(A, B)$. In the other seven cases, the severity of CAA varied from partial deposition of $A \beta(C, D)$ in small blood vessels (capillaries and arterioles) to complete $A \beta$ laden blood vessels in the leptomeninges $(F)$ and parenchyma $(H)$, which was often associated with $A P O E \in 4$ homozygosity $(\mathrm{E}-\mathrm{H})$. In these patients, a proportion of the CAA almost certainly pre-dates the trauma. Bars $=100 \mu \mathrm{m}$ in $A, C, E$, and $G$ and $10 \mu \mathrm{m}$ in $B, D, F$, and $H$.

(fig 1A, B). Thus CAA was detected in $7 / 40(18 \%) \in 4$ carriers but in only $1 / 48(2 \%)$ non- $\epsilon 4$ carriers $(p=0.021,95 \%$ CI for difference in proportions with CAA $3 \%$ to $29 \%$ ). Thus the relative risk of CAA in trauma cases possessing at least one $\epsilon 4$ allele was increased 8.4 fold compared with non- $\epsilon 4$ carriers. Among the patients with CAA, there were no carriers of the $A P O E \in 2$ allele.

\section{Relation between CAA and contusion index}

The relation between CAA and contusion index is shown in fig 2 . The data are positively skewed and the median total contusion index for the patients with CAA was 19 compared with 14.5 for the patients without CAA ( $p=0.23,95 \%$ CI for difference in medians -5 to 14 ). Detailed examination of the slides revealed no obvious pattern of anatomical association between the contusions and blood vessels displaying CAA.

Relation between APOE genotype and contusion index The total contusion index values were plotted in relation to $A P O E$ genotype in a dose specific manner (fig 3). Again the 
Table 1 Clinical detail of cases with and without cerebral amyloid angiopathy (CAA)

\begin{tabular}{|c|c|c|}
\hline & $\begin{array}{l}\text { CAA } \\
(n=8)\end{array}$ & $\begin{array}{l}\text { No CAA } \\
(n=80)\end{array}$ \\
\hline Median (range) age in years & $58(21-75)$ & $26.5(0-79)$ \\
\hline \multicolumn{3}{|l|}{ Cause of injury (n (\%)) } \\
\hline Fall & $4(50)$ & $29(36)$ \\
\hline Road traffic accident & $4(50)$ & $45(56)$ \\
\hline Assault & 0 & $6(8)$ \\
\hline Median (range) survival time in hours & $25.5(16-240)$ & $48(4-576)$ \\
\hline Median (range) contusion index & $19(0-54)$ & $14.5(0-46)$ \\
\hline $\mathrm{A} \beta$ plaques (n (\%)) & $7(88)$ & $17(21)$ \\
\hline \multicolumn{3}{|l|}{ APOE genotype (n (\%)) } \\
\hline$E 2,2$ & 0 & $2(2)$ \\
\hline $\mathrm{E} 2,3$ & 0 & $7(9)$ \\
\hline$E 2,4$ & 0 & $4(5)$ \\
\hline $\mathrm{E} 3,3$ & $1(12)$ & $38(48)$ \\
\hline $\mathrm{E} 3,4$ & $3(38)$ & $27(34)$ \\
\hline $\mathrm{E} 4,4$ & $4(50)$ & $2(2)$ \\
\hline \multicolumn{3}{|l|}{$A P O E$ allele frequency $(\mathrm{n} / \mathrm{N}(\%))$} \\
\hline$\epsilon 2$ & 0 & $15 / 160(9)$ \\
\hline$\epsilon 3$ & $5 / 16(31)$ & $110 / 160(69)$ \\
\hline$\epsilon 4$ & $11 / 16(69)$ & $35 / 160(22)$ \\
\hline
\end{tabular}

data were positively skewed. Non- $A P O E \in 4$ carriers $(\mathrm{n}=48)$ and $A P O E \in 4$ heterozygous cases $(\mathrm{n}=34)$ had similar median total contusion index values ( 14.5 and 12 , respectively). APOE $\epsilon 4$ homozygotes $(n=6)$ had a median total contusion index of 25, approximately double that of the other two groups: however, the small number of homozygotes was such that the difference between the medians of the three groups was not statistically significant $(p=0.057)$.

\section{DISCUSSION}

The results of the present study show that CAA is present in a relatively small proportion (9\%) of patients who have had a fatal head injury. It tended to be present in older patients (median age 58 years; range $21-75$ ), which is consistent with the known association between CAA and ageing. ${ }^{17}{ }^{18}$ Among head injured patients, CAA was considerably more likely to occur in those with a genetic predisposition conferred by possession of an $A P O E \in 4$ allele. Again this is consistent with previous studies, which have shown a strong association between CAA and APOE $\in 4 . .^{20}$ Of particular interest is the possibility that the presence of CAA in patients who experience a head injury may influence the clinical outcome. For example, blood vessels laden with amyloid may be more prone to rupture after trauma, resulting in haemorrhage. ${ }^{28} 29$ As this was a post-mortem study the only clinical outcome measure available was the survival time of the patients. The head injured cases with CAA had shorter survival time (median 25.5 hours; range 4 hours to 10 days) than trauma cases without CAA (median 48 hours; range 4 hours to 24 days) maybe indicating worse outcome, but because of the small number of cases and wide range in survival time this was not statistically significant.

In this study, the median total contusion index in the APOE $\epsilon 4$ homozygous head injured cases was approximately double that of the non-APOE $\in 4$ carriers and the heterozygotes although the small number of homozygotes meant that this was not statistically significant. There was no obvious association between the presence of CAA and the severity or extent of contusions, although again the number of cases with CAA was relatively small.

Clinical studies of survivors of head injury have shown that intracranial haematomas in carriers of $A P O E \in 4$ have significantly larger volume than in non-carriers of $A P O E$ $\epsilon 4 .{ }^{30}$ In addition a study of pathological features of traumatic brain injury in relation to $A P O E$ genotype found a significant

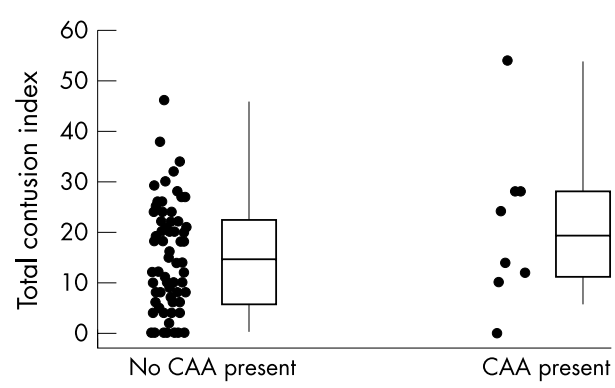

Figure 2 Dotplot (with $x$-axis random jitter to distinguish data points) and boxplot (showing the minimum, lower quartile, median, upper quartile and maximum values) of the total contusion index for those without and with cerebral amyloid angiopathy (CAA).

association between possession of $A P O E \in 4$ and moderate severe contusional and severe hypoxic brain damage, but not other forms of pathology. ${ }^{31}$ There is also evidence that differences in coagulation profile may contribute to the relationship between $A P O E \in 4$ and haemorrhage. ${ }^{32}$ It is possible that rigid, amyloid-laden blood vessels may be less haemodynamically reactive, perhaps impairing reactive changes in vascular tone and increasing vulnerability to ischaemia. These observations relating to pathological mechanisms seem likely to have clinical relevance because outcome studies indicate that head injured patients who are $A P O E \in 4$ carriers tend to fare worse than non-carriers of $A P O E$ $\epsilon 4^{1-324}$ and are also more prone to post-traumatic seizures.3.

Possession of APOE $€ 2$ appears to protect against Alzheimer's disease ${ }^{34}$ in which $\mathrm{A} \beta$ deposition is a major pathological feature, both in plaques and in the cerebral vasculature. Remarkably, patients with $A P O E \in 2$ who do develop CAA seem to be particularly prone to spontaneous haemorrhages ${ }^{25}{ }^{35-38}$ perhaps because of susceptibility to the development of CAA-associated vasculopathy. ${ }^{35}$ In the present study, in keeping with these observations, none of the cases with CAA were $A P O E \in 2$ carriers.

An alternative interpretation of our results revolves around CAA being a consequence of the trauma, particularly in the younger $\operatorname{cases}^{40}$ and in cases of dementia pugilistica ${ }^{41}$ perhaps reflecting deposition along perivascular drainage pathways as a result of increased $A \beta$ in the brain. Weller et $a l^{43}$ have proposed that the impairment of the periarterial fluid drainage pathway may be responsible for the development of CAA in Alzheimer's disease and in older people as it may reflect the failure to eliminate $A \beta$. Other hypotheses revolve around conditions that favour $A \beta$ fibrillogenesis (for example hypoxia, acidosis, altered proteolytic environment, impaired axonal transport) and the ability of smooth muscle cells to clear $\mathrm{A} \beta{ }^{44}$ Animal models of CAA have provided a

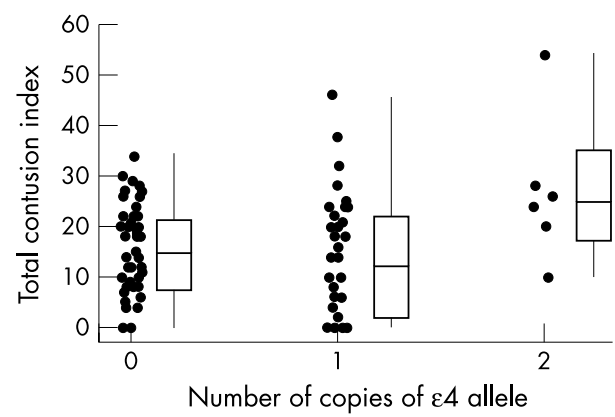

Figure 3 Dotplot (with $\mathrm{x}$-axis random jitter to distinguish data points) and boxplot (showing the minimum, lower quartile, median, upper quartile and maximum values) of the total contusion index for those with 0,1 , and 2 copies of the $A P O E \in 4$ allele. 
different perspective and also raise the possibility that CAA might occur as a consequence of head injury. Increased expression of cytokines is a feature of the response to head injury and increased expression of transforming growth factor (TGF)- $\beta$ in transgenic mice results in the development of CAA ${ }^{45}$ In addition, focal lesioning of the basal nucleus of Meynert in rabbits, the source of the cholinergic innervation of the cerebral cortex and vasculature, results in the formation of CAA accompanied by parenchymal plaques, within a few days. ${ }^{46}$ It is therefore of relevance that in humans the basal nucleus of Meynert is particularly susceptible to damage in severe head injury, particularly in the presence of raised intracranial pressure, brain swelling, and internal herniations resulting in a variety of haemorrhagic, ischaemic, and mechanical disturbances. ${ }^{47}$ There is evidence that the basal nucleus of Meynert, specifically, may be severely damaged in fatal head injury. ${ }^{48}$

In conclusion, CAA occurs in a small proportion of head injured patients, predominantly in $A P O E \in 4$ carriers. Although the CAA is likely to have been pre-existing in some of the older patients, the presence of leptomeningeal CAA in a 21 year old patient supports the concept that this pathology may have arisen de novo as a consequence of the trauma. However, although it seems there may be an association between $A P O E \in 4$ homozygosity and the severity of contusional damage, it remains unclear whether the CAA provides an anatomical substrate for the poor clinical outcome seen in these patients.

\section{Authors' affiliations}

\section{P D Leclercq, S M Gentleman, Division of Neuroscience and}

Psychological Medicine, Faculty of Medicine, Imperial College London, London, UK

L S Murray, D I Graham, University Academic Unit of Neuropathology, Institute of Neurological Sciences, Southern General Hospital, Glasgow, UK

C Smith, Neuropathology Lab., Department of Pathology, University of Edinburgh, Western General Hospital, Edinburgh, UK

J A R Nicoll, Clinical Neurosciences, University of Southampton, Southampton General Hospital, Southampton, UK

This study was funded in part by grants from the Medical Research Council (G9814486) and National Institute of Health (AG12411).

Competing interests: JARN and DIG are named applicants on the following patent: Method of prognosing chronic neurodegenerative pathology following a head injury. UK patent application 9415073.7 filed jointly by SmithKline Beecham and University of Glasgow on 27 July 1994; PCT worldwide application PCT/EP95/02827 filed on 13 July 1995; awarded 5 May 1998 (US5747260).

\section{REFERENCES}

1 Friedman G, Froom P, Sazbon L, et al. Apolipoprotein E-epsilon4 genotype predicts a poor outcome in survivors of traumatic brain injury. Neurology 1999;52:244-8.

2 Sorbi S, Nacmias B, Piacentini S, et al. ApoE as a prognostic factor for posttraumatic coma. Nat Med 1995;1:852.

3 Teasdale GM, Nicoll JA, Murray G, et al. Association of apolipoprotein E polymorphism with outcome after head injury. Lancet 1997;350:1069-71.

4 Alberts MJ, Graffagnino C, McClenny C, et al. ApoE genotype and survival from intracerebral haemorrhage. Lancet 1995;346:575.

5 McCarron MO, Muir KW, Weir CJ, et al. The apolipoprotein E epsilon4 allele and outcome in cerebrovascular disease. Stroke 1998;29:1882-7.

6 McCarron MO, Hoffmann KL, DeLong DM, et al. Intracerebral hemorrhage outcome: apolipoprotein E genotype, hematoma, and edema volumes. Neurology 1999;53:2176-9.

7 Dunn LT, Stewart E, Murray GD, et al. The influence of apolipoprotein E genotype on outcome after spontaneous subarachnoid hemorrhage: a preliminary study. Neurosurgery 2001;48:1006-10.

8 Niskakangas T, Ohman J, Niemela M, et al. Association of apolipoprotein E polymorphism with outcome after aneurysmal subarachnoid hemorrhage: a preliminary study. Stroke 2001;32:1181-4.

9 McCarron MO, Delong D, Alberts MJ. APOE genotype as a risk factor for ischemic cerebrovascular disease: a meta-analysis. Neurology 1999;53:1308-11.

10 Horsburgh K, McCarron MO, White F, et al. The role of apolipoprotein E in Alzheimer's disease, acute brain injury and cerebrovascular disease: evidence of common mechanisms and utility of animal models. Neurobiol Aging 2000;21:245-55

11 Kalaria RN. Advances in molecular genetics and pathology of cerebrovascular disorders. Trends Neurosci 2001;24:392-400.

12 Vinters HV. Cerebral amyloid angiopathy. A critical review. Stroke 1987; 18:311-24.

13 Yamada M. Cerebral amyloid angiopathy: an overview. Neuropathology 2000;20:8-22

14 Alonzo NC, Hyman BT, Rebeck GW, et al. Progression of cerebral amyloid angiopathy: accumulation of amyloid-beta 40 in affected vessels. J Neuropathol Exp Neurol 1998;57:353-9.

15 McCarron MO, Nicoll JA, Stewart J, et al. Amyloid beta-protein length and cerebral amyloid angiopathy-related haemorrhage. NeuroReport 2000;11:937-40.

16 Davis DG, Schmitt FA, Wekstein DR, et al. Alzheimer neuropathologic alterations in aged cognitively normal subjects. J Neuropathol Exp Neurol 1999:58:376-88.

17 Masuda J, Tanaka K, Ueda K, et al. Autopsy study of incidence and distribution of cerebral amyloid angiopathy in Hisayama, Japan. Stroke 1988; 19:205-10.

18 Vinters HV, Gilbert JJ. Cerebral amyloid angiopathy: incidence and complications in the aging brain. II. The distribution of amyloid vascular changes. Stroke 1983;14:924-8.

19 Schmechel DE, Saunders AM, Strittmatter WJ, et al. Increased amyloid betapeptide deposition in cerebral cortex as a consequence of apolipoprotein $\mathrm{E}$ genotype in late-onset Alzheimer disease. Proc Natl Acad Sci U S A 1993;90:9649-53

20 Greenberg SM, Rebeck GW, Vonsattel JP, et al. Apolipoprotein E epsilon 4 and cerebral hemorrhage associated with amyloid angiopathy. Ann Neurol 1995:38:254-9.

21 Olichney JM, Hansen LA, Galasko D, et al. The apolipoprotein E epsilon 4 allele is associated with increased neuritic plaques and cerebral amyloid angiopathy in Alzheimer's disease and Lewy body variant. Neurology 1996:47:190-6.

22 Premkumar DR, Cohen DL, Hedera P, et al. Apolipoprotein E-epsilon4 alleles in cerebral amyloid angiopathy and cerebrovascular pathology associated with Alzheimer's disease. Am J Pathol 1996;148:2083-95.

23 Coria F, Rubio I. Cerebral amyloid angiopathies. Neuropathol Appl Neurobiol 1996;22:216-27.

24 Nicoll JA, Roberts GW, Graham DI. Apolipoprotein E epsilon 4 allele is associated with deposition of amyloid beta-protein following head injury. Nat Med 1995; 1:135-7

25 Nicoll JA, Burnett C, Love S, et al. High frequency of apolipoprotein E epsilon 2 allele in hemorrhage due to cerebral amyloid angiopathy. Ann Neurol 1997;41:716-21.

26 Bancroft JD, Cook HC. Manual of histological techniques and their diagnostic applications. Edinburgh: Churchill Livingstone 1994:114-15.

27 Adams JH, Doyle D, Graham DI, et al. The contusion index: a reappraisal in human and experimental non-missile head injury. Neuropathol Appl Neurobiol 1985;11:299-308.

28 Dada MA, Rutherfoord GS. Medicolegal aspects of cerebral amyloid angiopathy. A case report. Am J Forensic Med Pathol 1993;14:319-22.

29 Wakui K, Seguchi K, Kuroyanagi T, et al. [Multiple intracerebral hemorrhages due to cerebral amyloid angiopathy after head trauma]. No Shinkei Geka 1988; 16:1287-91.

30 Liaquat I, Dunn LT, Nicoll JA, et al. Effect of apolipoprotein E genotype on hematoma volume after trauma. J Neurosurg 2002;96:90-6.

31 Smith C, Graham DI, Murray LS, et al. Association of APOE polymorphisms and pathological features in traumatic brain injury. Neuropathol Appl Neurobiol 2002;28:151-2.

32 Weir CJ, McCarron MO, Muir KW, et al. Apolipoprotein E genotype, coagulation, and survival following acute stroke. Neurology 2001;57:1097-100

33 Diaz-Arrastia R, Gong Y, Fair S, et al. Increased risk of late posttraumatic seizures associated with inheritance of APOE epsilon4 allele. Arch Neurol 2003;60:818-22

34 Chartier-Harlin MC, Parfitt M, Legrain S, et al. Apolipoprotein E, epsilon 4 allele as a major risk factor for sporadic early and late-onset forms of Alzheimer's disease: analysis of the 19q13.2 chromosomal region. Hum Mol Genet 1994;3:569-74.

35 Greenberg SM, Vonsattel JP, Segal AZ, et al. Association of apolipoprotein E epsilon2 and vasculopathy in cerebral amyloid angiopathy. Neurology 1998;50:961-5.

36 McCarron MO, Nicoll JA. High frequency of apolipoprotein E epsilon 2 allele is specific for patients with cerebral amyloid angiopathy-related haemorrhage. Neurosci Lett 1998;247:45-8.

37 McCarron MO, Nicoll JA, Ironside JW, et al. Cerebral amyloid angiopathy related hemorrhage. Interaction of APOE epsilon2 with putative clinical risk factors. Stroke 1999;30:1643-6.

38 O'Donnell HC, Rosand J, Knudsen KA, et al. Apolipoprotein E genotype and the risk of recurrent lobar intracerebral hemorrhage. N Engl J Med 2000;342:240-5.

39 McCarron MO, Nicoll JA, Stewart J, et al. The apolipoprotein E epsilon2 allele and the pathological features in cerebral amyloid angiopathy-related hemorrhage. J Neuropathol Exp Neurol 1999;58:711-18.

40 Gentleman SM, Greenberg BD, Savage MJ, et al. A beta 42 is the predominant form of amyloid beta-protein in the brains of short-term survivors of head injury. NeuroReport 1997;8:1519-22.

41 Jordan BD, Relkin NR, Ravdin LD, et al. Apolipoprotein E epsilon4 associated with chronic traumatic brain injury in boxing. JAMA 1997;278:136-40 
42 Tokuda T, Ikeda S, Yanagisawa N, et al. Re-examination of ex-boxers' brains using immunohistochemistry with antibodies to amyloid beta-protein and tau protein. Acta Neuropathol (Berl) 1991;82:280-5.

43 Weller RO, Massey A, Kuo YM, et al. Cerebral amyloid angiopathy: accumulation of $A$ beta in interstitial fluid drainage pathways in Alzheimer's disease. Ann N Y Acad Sci 2000;903:110-17.

44 Prior R, Wihl G, Urmoneit B. Apolipoprotein E, smooth muscle cells and the pathogenesis of cerebral amyloid angiopathy: the potential role of impaired cerebrovascular A beta clearance. Ann N Y Acad Sci 2000;903:180-6.
45 Wyss-Coray T, Masliah E, Mallory M, et al. Amyloidogenic role of cytokine TGF-betal in transgenic mice and in Alzheimer's disease. Nature 1997;389:603-6.

46 Beach TG, Potter PE, Kuo YM, et al. Cholinergic deafferentation of the rabbit cortex: a new animal model of Abeta deposition. Neurosci Lett 2000;283:9-12

47 Graham DI, Adams JH, Nicoll JA, et al. The nature, distribution and causes of traumatic brain injury. Brain Pathol 1995;5:397-406.

48 Murdoch I, Nicoll JA, Graham DI, et al. Nucleus basalis of Meynert pathology in the human brain after fatal head injury. J Neurotrauma 2002;19:279-84.

\section{Clinical Evidence - Call for contributors}

Clinical Evidence is a regularly updated evidence-based journal available worldwide both as a paper version and on the internet. Clinical Evidence needs to recruit a number of new contributors. Contributors are healthcare professionals or epidemiologists with experience in evidence-based medicine and the ability to write in a concise and structured way.

\section{Areas for which we are currently seeking authors:}

- Child health: nocturnal enuresis

- Eye disorders: bacterial conjunctivitis

- Male health: prostate cancer (metastatic)

- Women's health: pre-menstrual syndrome; pyelonephritis in non-pregnant women

However, we are always looking for others, so do not let this list discourage you.

Being a contributor involves:

- Selecting from a validated, screened search (performed by in-house Information Specialists) epidemiologically sound studies for inclusion.

- Documenting your decisions about which studies to include on an inclusion and exclusion form, which we keep on file.

- Writing the text to a highly structured template (about 1500-3000 words), using evidence from the final studies chosen, within 8-10 weeks of receiving the literature search.

- Working with Clinical Evidence editors to ensure that the final text meets epidemiological and style standards.

- Updating the text every six months using any new, sound evidence that becomes available. The Clinical Evidence in-house team will conduct the searches for contributors; your task is simply to filter out high quality studies and incorporate them in the existing text.

- To expand the topic to include a new question about once every 12-18 months.

If you would like to become a contributor for Clinical Evidence or require more information about what this involves please send your contact details and a copy of your CV, clearly stating the clinical area you are interested in, to Klara Brunnhuber (kbrunnhuber@ bmigroup.com).

\section{Call for peer reviewers}

Clinical Evidence also needs to recruit a number of new peer reviewers specifically with an interest in the clinical areas stated above, and also others related to general practice. Peer reviewers are healthcare professionals or epidemiologists with experience in evidence-based medicine. As a peer reviewer you would be asked for your views on the clinical relevance, validity, and accessibility of specific topics within the journal, and their usefulness to the intended audience (international generalists and healthcare professionals, possibly with limited statistical knowledge). Topics are usually 1500-3000 words in length and we would ask you to review between 2-5 topics per year. The peer review process takes place throughout the year, and our turnaround time for each review is ideally 10-14 days.

If you are interested in becoming a peer reviewer for Clinical Evidence, please complete the peer review questionnaire at www.clinicalevidence.com or contact Klara Brunnhuber (kbrunnhuber@bmigroup.com). 